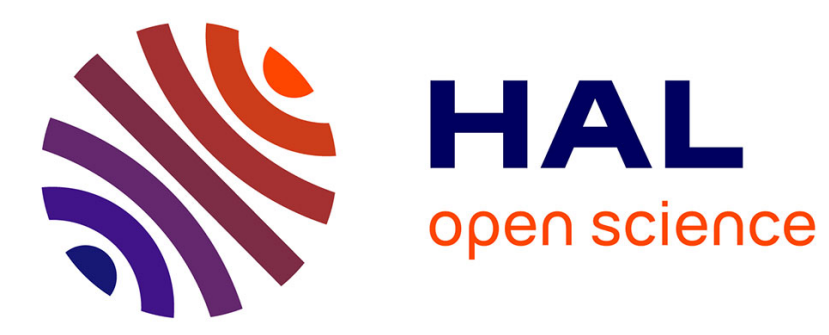

\title{
Foi et croyance au Moyen Âge. Les médiations liturgiques
}

Eric Palazzo

\section{To cite this version:}

Eric Palazzo. Foi et croyance au Moyen Âge. Les médiations liturgiques. Annales. Histoire, Sciences sociales, 1998, 53 (6), pp.1131-1154. 10.3406/ahess.1998.279718 . halshs-01340682

\section{HAL Id: halshs-01340682 \\ https://shs.hal.science/halshs-01340682}

Submitted on 1 Jul 2016

HAL is a multi-disciplinary open access archive for the deposit and dissemination of scientific research documents, whether they are published or not. The documents may come from teaching and research institutions in France or abroad, or from public or private research centers.
L'archive ouverte pluridisciplinaire HAL, est destinée au dépôt et à la diffusion de documents scientifiques de niveau recherche, publiés ou non, émanant des établissements d'enseignement et de recherche français ou étrangers, des laboratoires publics ou privés. 


\section{Foi et croyance au Moyen Âge. Les médiations liturgiques}

\section{Monsieur Éric Palazzo}

\section{Résumé}

Faith and Belief in the Middle Ages: Liturgical Mediations. E. Palazzo.

The article examines the different liturgical modes of transmission of faith in the Middle Ages. The inquiry leaves the impression of a liturgical triptych wich describes the actual reception of faith by the faithful. The first panel is made up of the liturgical texts themselves which express the orthodoxy of faith as defined by the Church. The second panel contains the normative texts by which the ecclesiastical authorities attempt to harmonise liturgical practice with the content of the sacred pieces. The third panel of the triptych, containing diverse texts (hagiographical...) and images, opens the dimension of the senses by which the liturgy is ' lived", a dimension indispensable for the transmission of faith.

\section{Citer ce document / Cite this document :}

Palazzo Éric. Foi et croyance au Moyen Âge. Les médiations liturgiques. In: Annales. Histoire, Sciences Sociales. 53e année, N. 6, 1998. pp. 1131-1154;

doi : 10.3406/ahess.1998.279718

http://www.persee.fr/doc/ahess_0395-2649_1998_num_53_6_279718

Document généré le 14/03/2016 


\section{TRANSMETTRE LA FOI \\ $A \cup M O Y E N A G E$}

\section{FOI ET CROYANCE AU MOYEN AGE Les médiations liturgiques}

Éric Palazzo

Pour Salomé

«Transmettre la foi au Moyen Age »', le titre du dossier dans lequel s'insère cet article fait écho au « faire croire », rendu célèbre par un colloque tenu voici quelques années à Rome, si bien que l'on peut s'interroger pour savoir s'il ne s'agit pas là d'une autre manière de poser la même question à laquelle de savantes contributions de ce colloque avaient tenté de répondre'. C'est une évidence, la liturgie se situe au cœur du débat sur la transmission de la foi au Moyen Age, de même que son rôle dans le « faire croire » est central. Pourtant, en préalable à ce qui va suivre, on est en droit de se demander si «transmettre la foi » équivaut à «faire croire », du moins dans le christianisme médiéval. De nombreux auteurs se sont penchés sur la question et ont apporté des réponses diverses dans les domaines de la théologie et de l'histoire sociale notamment. En tête de cet article, un rappel succinct des éléments essentiels de ces contributions permettra de ne pas m'aventurer sur le terrain sensible de la définition de la foi dans l'Antiquité et au Moyen Age. Ce contournement s'explique par le souhait de ne pas répéter ce que d'autres ont dit sur ce point - s'il fallait prendre position, ce serait l'objet d'un autre article - et surtout par le désir de suggérer un autre angle problématique. Je me propose en effet d'examiner les médiations liturgiques de l'Antiquité et du Moyen Age dans leur rapport à la transmission de la foi. Parler des médiations liturgiques implique forcément d'avoir une conception large de la liturgie et de ses manifestations. Dans cette optique, je m'attacherai aussi bien à des textes de nature variée (hagiographie, chroniques...), à l'iconographie qu'aux sources litur-

1. Je remercie vivement mes collègues et amis Jérôme Baschet, Paul De Clerck, François Héber-Suffrin. Dominique Iogna-Prat et Jacques-Hubert Sautel d'avoir bien voulu relire et critiquer cet article.

2. Faire croire. Modalités de la diffusion et de la réception des messages religieux du XII" au XV' siècle, Rome, 22-23 juin 1979, "Collection de l'Ecole française de Rome 51 », Rome, 1981. 
giques à proprement parler. Je considère essentiel d'échapper à une vision trop étroite du rapport entre foi et liturgie dans la société médiévale ; vision qui serait uniquement fondée sur la double approche théologique et anthropologique, ainsi que sur l'analyse des textes liturgiques ou normatifs dans leurs rapports avec la réalité sociale et politique.

Tout d'abord, l'analyse conjointe de certains textes liturgiques et de textes normatifs, relevant de la description (ou plutôt de la prescription) de la pratique, permettra de saisir les tensions ressenties dans l'examen préalable du rapport entre foi et croyance, de même qu'elle fera mieux entrevoir la façon dont la liturgie, ou la ritualité chrétienne dans son ensemble, a pour ainsi dire "géré » ce rapport. Ancrée dans l'histoire, la liturgie, à travers sa codification, elle-même expression à divers degrés de la foi, reflète de manière plus ou moins marquée les grandes étapes de l'évolution sociale et politique de la société médiévale. Ainsi, l'analyse de ces textes fera surgir les liens, souvent très étroits, établis, notamment au Moyen Age, entre liturgie et histoire sociale, montrant parfois de fortes implications du « social » dans la définition de la foi, ou de sa codification, dans la liturgie.

Ensuite, il faudra examiner dans des textes hagiographiques, ou apparentés, la façon dont les ambiguïtés relevant de la pratique de la liturgie, en accord ou non avec la définition de la foi, se trouvent plus ou moins résolues dans ces écrits d'une autre nature que des textes liturgiques stricto sensu et autres codifications normatives.

Enfin, en accord avec la place grandissante que lui consacre l'historien dans ses entreprises ${ }^{3}$, je me propose de traiter de la liturgie, de la foi et des images. Sans prétendre brosser, même à grands traits, une histoire de la foi et de sa transmission au Moyen Age à travers les images, ce qui serait bien présomptueux en quelques pages, je voudrais plus modestement mettre en évidence les mécanismes qui ont prévalu dans le traitement iconographique de certaines images «liturgiques » afin qu'elles servent de relais efficace entre la définition de la foi par les théologiens et sa codification dans les rites chrétiens.

Aux yeux du théologien, voire du liturgiste du Moyen Age, la dimension personnelle de la foi s'accorde parfaitement avec la démarche tant intellectuelle que spirituelle lui permettant de proposer une définition de celleci. Pour l'homme du Moyen Age, cette constatation apparaîtrait largement dénuée de sens car c'est sa manière de vivre pleinement sa foi. En revanche, pour l'historien du $20^{\mathrm{e}}$ siècle vivant dans un monde largement déchristianisé et même « déspiritualisé », au moins pour les pays occidentaux, la question du rapport entre son travail scientifique et sa foi personnelle se pose en des termes bien différents. On a longtemps prétendu (ou pensé sans le dire) cela relève-t-il d'un phénomène de générations ? - que l'étude de la foi et de ses manifestations, parmi lesquelles la liturgie, dans les sociétés

3. Voir le récent dossier publié par les Annales HSS, 1996, avec les articles de J. BASCHET, J.-C. BONNE et J.-C. SCHMITT ainsi que L'image. Fonctions et usages des images dans l'Occident médiéval, sous la direction de J. B ASCheT et J.-C. SCHMITT, Paris, Le Léopard d'Or, « Cahiers du Léopard d'or-5 », 1996. 
anciennes, en particulier le Moyen Age chrétien, n'était possible que si elle était pratiquée par des historiens croyants ${ }^{4}$. Pourtant, une nouvelle génération de chercheurs aborde la question sous un autre angle. En effet, laissant de côté la dimension personnelle de la foi, il s'agit plutôt de tenter d'entrer dans l'intelligence de la foi des hommes du Moyen Age ${ }^{5}$ tout en échappant à la continuité historique menant jusqu'à nos jours. Certains affirmeront sans aucun doute que l'intelligence de la foi des hommes du passé ne peut être perçue que si l'on fait intervenir ses propres sentiments, mais l'historien risque aujourd'hui un autre défi.

En d'autres termes, je souhaite vivement que la présente contribution s'inscrive dans cette optique nouvelle du travail de l'historien sur la foi.

\section{Définition et évolution des concepts de foi et de croyance pendant l'Antiquité et le Moyen Age}

Pendant l'Antiquité et une grande partie du Moyen Age, «croire » n'implique pas obligatoirement avoir la foi. Analysant la naissance du concept de croyance entre le $12^{\mathrm{e}}$ et le $17^{\mathrm{e}}$ siècle, Jean Wirth a remarquablement éclairé les usages respectifs de foi et de croyance, au Moyen Age notamment ${ }^{6}$. Ignorant la notion même de croyance, la scolastique médiévale employait dans des sens multiples (spirituel, social, par exemple) la notion de fides. De son côté, l'émergence de la croyance se situe, selon Wirth, dans un univers social, principalement celui des $12^{e}-13^{e}$ siècles, où le pouvoir de l'Église se ramifie jusqu'à prendre possession des croyances populaires ${ }^{7}$.

De leur côté, sociologues et linguistes s'accordent à considérer «le croire » comme un champ sémantique d'une richesse peu commune ${ }^{8}$. Le christianisme, comme d'autres religions, propose des objets de croyance ou bien à propos desquels s'applique la foi dont la connaissance passe par la

4. L'historien et la foi, Jean Delumeau (dir.), Paris, 1996, dans lequel on trouve les contributions, souvent marquées par les opinions personnelles, de Pierre Chaunu, Jacques Fontaine, Michel Mollat du Jourdin, René Rémond, Pierre Riché ; voir la présentation de cet ouvrage par A. VAuChEZ, Le Monde, 12.7.1996.

5. Cf. P.-M. GY, "La tâche du liturgiste », La liturgie dans l'histoire, Paris, 1990, pp. 321 324.

6. J. WIRTH, «La naissance du concept de croyance (XII"-XVII" siècles) », Bibliothèque d'Humanisme et Renaissance, XLIV, 1983, pp. 7-58.

7. J. WIRTH, art. cité, p. 57 ; voir aussi J.-C. SCHMITT, «La croyance au Moyen Age », Raison présente, 113, 1995, pp. 5-22 et «Du bon usage du Credo », Faire Croire..., op. cit., pp. 337-361, ainsi que le récent panorama de R. N. SWANSON, Religion and Devotion c. 1215c. 1515, Cambridge, 1996, pp. 10-89. En pendant à la croyance, la seconde moitié du Moyen Age a vu se développer les superstitions, croyances que l'Église n'a pas cherché à intégrer dans ses pratiques, J.-C. SCHMITT, «Les superstitions », Histoire de la France religieuse, t. I, J. Le GofF, R. Rf́mond (dir.), Paris, 1988, pp. 419-551.

8. M. Dellaunay, "Comprendre le croire. Verbe opérateur, philosophèmes », La croyance, "Philosophie 7 », Paris, 1982, pp. 203-220. M. de CFrteau, "Une pratique sociale de la différence : croire », Faire croire..., op. cit., pp. 363-383. 
théologie", véritable "science de Dieu », et, d'une certaine manière, à travers la liturgie ${ }^{10}$. Simplement, aux yeux du sociologue, celle-ci demeure marquée par la reconnaissance sociale de l'efficacité symbolique de la ritualité, reconnaissance conditionnée par ce que Pierre Bourdieu a appelé «le langage autorisé »"1.

Aux yeux du théologien, en revanche, la foi est une condition préalable à la liturgie qui, dans un certain sens, apparaît comme une confirmation et un entérinement de la foi ${ }^{12}$. Chez les chrétiens, ce sont les sacrements, à travers les célébrations liturgiques, qui constituent et structurent la foi ${ }^{13}$. Dans la Bible, la foi en Dieu s'exprime différemment selon que l'on a affaire à des passages de l'Ancien Testament, où il s'agit plutôt de mettre en valeur la confiance en Dieu, ou bien aux textes du Nouveau Testament ${ }^{14}$, caractérisés par un phénomène d'agrégation, posant la foi comme un acte social, impliquant la permanence de la confiance en Dieu : «La foi est une manière de posséder déjà ce que l'on espère, un moyen de connaître des réalités que l'on ne voit pas. C'est elle qui valut aux anciens un bon témoignage » (Hébreux, 11, 1-2) ${ }^{15}$. Dans la Bible et les premiers textes

9. Parmi la vaste bibliographie sur le sujet, on consultera avec profit, Y. Congar, La foi et la théologie, Paris, 1962, H. DF LUBAC, La foi chrétienne. Essai sur la structure du Symbole des Apôtres, Paris, 1969.

10. Voir entre autres, G. LUKKEN, «La liturgie, moyen d'expression irremplaçable de la foi », Concilium, 82, 1973, pp. 11-23, I.-H. DaLmaIs, «L'expression de la foi dans les liturgies orientales », ibid., pp. 77-84, D. Power, "Deux expressions de la foi : culte et théologie», ibid., pp. 95-101.

11. P. Bourdit: "Le langage autorisé. Note sur les conditions sociales de l'efficacité du discours rituel », Actes de la Recherche en Sciences sociales, 5-6, nov. 1975, pp. 183-190) (texte repris dans Ce que parler veut dire, Paris, 1982, pp. 103-119), du même auteur, à propos de la définition du « langage autorisé » de l'Église, voir aussi « Genèse et structure du champ religieux ", Revue française de Sociologie, XII, 1971, pp. 295-334.

12. Parmi la foisonnante bibliographie, voir récemment J.-Y. HAMFi.INF, « La foi sur son axe fondamental ", La Maison-Dieu, 174, 1988, pp. 59-73 et F. Bousquer, "La foi chrétienne dans sa spécificité », ibid., pp. 21-58.

13. Cf. L.-M. Chauvet, « La structuration de la foi dans les célébrations sacramentelles », ibid., pp. 75-95. Voir aussi M.-D. ChENu, «Foi et sacrement », La Maison-Dieu, 71, 1962, pp. 69-77. M.-T. Nadeau, Foi de l'Église. Évolution et sens d'une formule, "Théologie historique 78 », Paris, 1988 et son article, proposant une synthèse du livre, "Le développement et l'expression Fides Ecclesiae », La Maison-Dieu, 174, 1998, pp. 136-152.

14. Art. «Foi », Dictionnaire de spiritualité, t. V, 1964, col. 529-19 et art. «Foi », Dictionnaire de théologie catholique, VI/1, col. 55-514; B. WAWTER, "Le développement de l'expression de la foi dans la communauté en prière. 1. Dans le Nouveau Testament », Concilium, 82, 1973, pp. 25-31. Voir aussi les remarques d'Y. CONGAR, "Les normes de fidélité et d'identité chrétiennes à travers l'histoire de l'Église ", Concilium, 83, 1973, pp. 11-22.

15. L'invisibilité de l'objet de la foi développée dans ce passage biblique sera largement répandue parmi les théologiens de l'Antiquité et du Moyen Age, depuis Augustin ("Fides est virtus qua credentur quae non videntur», PL. 40, col. 234) jusqu'à Thomas d'Aquin, en passant par Isidore de Séville, "Fides est qua veraciter credimus id quod nequaquam videre valeamus. Nam credere iam non possimus quod videmus. Proprie autem non fidei inde est dictum, si omnino fiat quod dictum est aut promissum. Et inde fides vocata, ab eo quod fit illud quod inter utrosque placitum est, quasi inter Deum et hominem; hinc et foedus ", Etym., VIII-2, 4, par Raban Maur qui reprend mot pour mot la définition d'ISIDORE (De Universo, PL. 111, col. 90). 
chrétiens ${ }^{16}$, la foi (fides) s'emploie aussi pour exprimer un don, une grâce ; elle enseigne et fait comprendre la révélation. N'étant pas seulement une affaire intérieure, elle doit aussi se manifester par la parole menant à la prière et à la confession de foi ${ }^{17}$.

Dans les plus anciens textes chrétiens à caractère liturgique, telles que la prétendue «Tradition apostolique » et les Constitutions apostoliques, on cherche fréquemment à expliquer l'orthodoxie chrétienne par la définition de la foi. «Mais nous, enfants de Dieu et fils de la paix, nous prêchons la sainte et droite doctrine de la foi : nous annonçons un seul Dieu, Seigneur de la Loi et des Prophètes, Créateur des êtres, Père du Christ, [...] ${ }^{18}$; pour les nouveaux venus à la foi, on s'assure de leur intégrité morale et spirituelle de même qu'on s'interroge sur les motifs qui les amènent à la foi ${ }^{19}$. Dans un autre contexte, un sermon adressé au peuple, Césaire d'Arles (469/70542) se risque à un exposé détaillé sur la foi et à une interprétation de ce mot $^{20}$. Il affirme clairement que sans la foi, rien n'est possible envers Dieu : "Et parce que foi tire son nom de fit (" est fait"), comme je l'ai dit plus haut, tu as beau dire mille fois que tu as la foi, si tu n'as pas voulu accomplir par des œuvres ce que tu promets en paroles, ce n'est pas du tout de la foi $\gg^{21}$.

Les théologiens des $12^{\mathrm{e}}$ et $13^{\mathrm{e}}$ siècles, s'inscrivant dans la lignée de l'époque patristique, discutent de la foi à partir des trois sens donnés au verbe «croire »: Credere Deo, c'est-à-dire croire ce qu'il (Dieu) dit; Credere Deum, croire qu'il est Dieu ; Credere in Deum, se donner à lui, $\mathrm{s}^{\prime}$ incorporer à ses membres ${ }^{22}$. Selon nombre de savants, les discussions

16. Voir le dossier réuni dans A. BLAISE, Le vocabulaire latin des principaux thèmes liturgiques, Turnhout, 1966, pp. 153-155, 598-602. Voir aussi R. MODRAS, «Fonctions et limites des énoncés de la foi », Concilium, 138, 1978, pp. 49-58.

17. Sur les rapports entre la foi et la prière saint Augustin affirme "fides fons orationis" (sermon 115, PL. 38, col. 655); sur la confession et la foi, particulièrement importante dans les premiers siècles chrétiens puis à partir de Latran IV (1215), A. Brekelmans, " Professions de foi dans l’Église primitive. Origine et fonction», Concilium, 51, 1970, pp. 33-41, E. COTHENET, «Liturgie et vie chrétienne d'après I Pierre ", La liturgie. Expression de la foi, Conférences Saint-Serge, XXV" semaine d'études liturgiques, Paris, 1978, « Bibliotheca "Ephemerides Liturgicae" - subsidia 16 ", Rome, 1979, pp. 97-113, en particulier pp. 107-112.

18. Les Constitutions Apostoliques, t. II, Livres III-VI, introduction, texte critique, traduction et notes par M. MetzGer, "Sources chrétiennes 329 », Paris, 1986, pp. 323-327.

19. «Des nouveaux venus à la foi. Ceux qui se présentent pour la première fois afin d'entendre la parole seront amenés tout d'abord devant les docteurs avant que tout le peuple n'arrive, et on leur demandera la raison pour laquelle ils viennent à la foi [...] », HiPPOLYTE: DE ROME, La tradition apostolique, introduction, traduction et notes par B. Botte, "Sources chrétiennes 11 bis ", Paris, 1968, p. 69 ; sur ce texte et son auteur présumé qui ont tant fait couler d'encre, M. MEtzgtr, "A propos des règlements ecclésiastiques et de la prétendue Tradition apostolique", Revue des Sciences religieuses, 66, 1992, pp. 249-261 (avec la référence aux autres contributions du même auteur à ce texte) et J.-P. BOLHOT, «L'auteur romain des Philosophumena et l'écrivain Hippolyte », Ecclesia Orans, 13, 1996, pp. 137-164.

20. CÉSAIRE D ARLES, Sermons au peuple, t. I, introduction, traduction et notes par M.-J. Delage, "Sources chrétiennes 175 », Paris, 1971, pp. 399-415.

21. Ibid., p. 403.

22. Cf. T. Camelot, "Credere Deo, credere Deum, credere in Deum. Pour l'histoire d'une formule traditionnelle", Revue des Sciences philosophiques et théologiques, 30, 1941-1942, 
théologiques de saint Thomas d'Aquin, entre autres, ont été préparées par certaines formules d'Abélard et d'Hugues de Saint-Victor affirmant que la foi est une adhésion «intelligente ${ }^{23}$. Ainsi, au moins dans la théologie scolastique, se trouvent réconciliées l'intelligence et la foi, car pour les théologiens du Moyen Age, la seconde est en quête de la première : "fides quaerens intellectum ${ }^{24}$.

\section{L'expression de la foi dans la liturgie: textes sacrés et textes normatifs}

«Lex orandi; lex credendi», cet adage, remontant sans doute au $5^{\mathrm{e}}$ siècle et sorti de la plume de Prosper d'Aquitaine, est bien connu de tous les liturgistes ${ }^{25}$. Il est apparu dans un contexte de controverse semipélagienne où Prosper ne faisait que reprendre les positions défendues par son maître Augustin lorsque celui-ci affirmait, cette fois contre les pélagiens : c'est la prière elle-même qui est la preuve la plus éclatante de la grâce. Comme l'a montré Paul De Clerck, la postérité de l'adage, voire ses aménagements de sens, aux $19^{\mathrm{e}}$ et $20^{\mathrm{e}}$ siècles, rend particulièrement sensible, aux yeux de l'historien, la perpétuation de l'idée selon laquelle la liturgie, avant toute autre chose, exprime la foi. Dans les premiers siècles chrétiens, l'attention du clergé, en premier lieu les évêques, s'est essentiellement portée sur la composition de prières qui puissent en même temps être de qualité et présenter les garanties nécessaires à l'expression de la foi ${ }^{26}$. Ainsi, à cette époque $\left(3^{\mathrm{e}}-5^{\mathrm{e}}\right.$ siècles $)$, on a veillé avec beaucoup de soin à ce que les prières, les oraisons, soient en accord avec l'orthodoxie définie par l'Église ${ }^{27}$. Parmi les prières célèbres de l'Antiquité, il faut réserver un sort particulier à la Prière universelle ${ }^{28}$. Désignant la prière que doit faire l'en-

pp. 149-155 et C. Mohrmann, «Credere in Deum. Sur l'interprétation théologique d'un fait de langue », Mélanges $J$. de Ghellinck S. J., t. I, Gembloux, 1951, pp. 277-285 (texte repris dans Etudes sur le latin des chrétiens, t. I, Rome, 1961, pp. 195-203). Sur la perpétuation de ces définitions de la foi, par l'intermédiaire de ces trois expressions, cf. Guillaume Durand, Rationale divinorum officiorum, I-IV, A. Davrit, T. M. Thibodfau (éds), "Corpus Christianorum - Continuatio Mediaevalis CXL", Turnhout, 1995, p. 368.

23. Voir en particulier M.-D. ChENU, « La psychologie de la foi dans la théologie du XIII' siècle », Études d'histoire littéraire et doctrinale du XIII" siècle, II, 1932, pp. 163-191.

24. Cette réconciliation entre la foi et l'intelligence a été fortement nourrie, au cours du $20^{\mathrm{e}}$ siècle, par la pensée de théologiens tels que le Père Chenu; voir, par exemple, son recueil d'articles, au titre évocateur: La Parole de Dieu, 1. La foi dans l'intelligence, "Cogitatio Fidei $10 »$, Paris, 1964.

25. Cf. P. DE CleRCK, "Lex orandi, lex credendi. Sens originel et avatars historiques d'un adage équivoque ", Questions liturgiques, 1978, pp. 193-212.

26. C. HANSON, «The Liberty of the Bishop to improvise Prayer in the Eucharist », Vigiliae Christianae, 15, 1961, pp. 173-176.

27. M. Vos, «A la recherche de normes pour les textes liturgiques de la messe (V $\mathrm{V}^{\mathrm{e}}-\mathrm{VII}^{\mathrm{e}}$ siècle) », Revue d'Histoire ecclésiastique, 69, 1974, pp. 5-37.

28. P. DE CLERCK, La « prière universelle » dans les liturgies latines anciennes. Témoignages patristiques et textes liturgiques, "Liturgiewissenschaftliche Quellen und Forschungen 62 », Münster, 1977 et son article de synthèse, «La prière universelle, expression de la foi », La liturgie expression de la foi, art. cité, pp. 129-146. 
semble des fidèles — on l'appelle aussi « prière des fidèles » — elle exprime la mise en œuvre de la foi en acte par la prière. Située à la messe, au moins dans l'Antiquité, entre les lectures et l'Eucharistie, il s'agit d'une prière d'intercession en faveur de plusieurs bénéficiaires. Au premier rang de ceux-ci, on trouve les incroyants et les hérétiques, ce qui prouve bien que l'adhésion à la foi dépend de Dieu, dans la prière qu'on lui adresse. En effet, l'objet de la prière porte ici sur l'obtention de la foi pour les incroyants. Les autres principaux bénéficiaires de cette prière sont les croyants, pour qu'ils persévèrent dans leur foi, les catéchumènes, les rois, les ennemis. Fondamentalement, la Prière universelle sert l'idée de l'unité nécessaire pour l'Église, comme elle cherche à souder les liens entre ses membres afin de faire régner la paix. Ajoutons encore, et ceci est important pour comprendre la relative disparition de cette prière au Moyen Age, que la Prière universelle se trouve profondément ancrée dans la culture de l'Antiquité chrétienne, marquée par la conversion et la recherche d'unité dans l'Église. Dans ce cas, c'est en quelque sorte la prière, acte de foi, qui permet d'atteindre les objectifs recherchés par l'Église : l'adhésion à Dieu et au Christ. Étant donné cette situation propre au christianisme des premiers siècles, on perçoit mieux les raisons pour lesquelles le Moyen Age n'a pratiquement plus fait usage de ce genre de prières ${ }^{29}$.

Dans l'euchologie du Haut Moyen Age, l'ensemble des prières reconnues par l'Église et contenues dans le sacramentaire du Haut Moyen Age, qui deviendra par la suite le missel, l'expression de la foi est pour ainsi dire permanente. Elle y prend des formes diverses, de richesses inégales, correspondant au jour liturgique et à son importance pour la liturgie de l'Église ${ }^{30}$. D'une manière générale, les prières soulignent trois aspects de la foi : 1. l'aspect personnel de la foi, considérée dans son aspect intérieur et efficace pour la vie du chrétien ; 2 . l'aspect efficace de la foi, portant le baptisé vers l'action dans le monde, en faveur du Christ ; 3. l'aspect communautaire, impliquant la participation de chacun dans la communauté de l'Église ${ }^{31}$. L'euchologie exprime encore la plénitude et l'intégrité de la foi, son unité et son authenticité. Les multiples emplois du mot fides dans la tradition euchologique romaine permettent de souligner les points suivants : conversion de l'incroyant; la foi comme itinéraire qui ne cesse jamais et permettant de comprendre la perspective eschatologique ; croissance de la foi impliquant la recherche de sa maturité ; relation étroite entre les vertus "fides-spes-caritas" propres au chrétien; la foi est reçue comme un don

29. Au Moyen Age, on constate la survie de ces formulaires, adaptés à des utilisations nouvelles dans les oraisons pascales gallicanes et hispaniques, les litanies accompagnant les processions et les prières et litanies des saints, cf. DE CI.ERCK, La "prière universelle... », op. cit., p. 314.

30. Voir les références des oraisons des sacramentaires romains, J. DESHUSSES, B. DARRAGON, Concordances et tableaux pour l'étude des grands sacramentaires, t. III-2, "Spicilegii friburgensis - subsidia $12 »$, Fribourg, 1983, pp. 145-150.

31. A. TRIACCA, «Fides magistra omnium credentium. Pédagogie liturgique : pédagogie de la foi ou par la foi ? (Contribution des sources liturgico-euchologiques à l'intelligence d'un problème actuel) », La liturgie. Expression de la foi, op. cit., pp. 265-310. 
qui pousse vers l'action; enfin, et je serais tenté de dire surtout, la liturgie, dans ses prières, exprime la foi de l'Église ${ }^{32}$. Fides Ecclesiae, tel est bien le moteur dynamique de la liturgie, et ceci est particulièrement visible dans l'euchologie et les formules sacramentelles en général, notamment au moment du baptême ${ }^{33}$. Curieusement, la formule « Fides Ecclesiae » n'apparaît qu'une seule fois dans le contenu d'une prière "officielle », probablement du $11^{\mathrm{e}}$ siècle et originaire d'Allemagne : "Seigneur Jésus Christ qui as dit à tes apôtres: " je vous laisse la paix, je vous donne ma paix": ne regarde pas nos péchés mais la foi de ton Église ${ }^{34}$. Il s'agit d'une oraison de paix, précédant le baiser, qui a été transmise dans le missel de saint Pie V (1570) mais avec un changement de fonction puisque, dans ce livre, elle est la première des trois oraisons adressées au Christ et prononcées à voix basse.

Certaines prières encore contiennent des allusions à la foi dont le sens ne se comprend qu'à partir du symbolisme des rites liturgiques. Par exemple, lors de la consécration d'un évêque, dans la prière prononcée par le célébrant au moment de la remise de l'anneau, signe tangible du mariage symbolique de ce dernier avec son Église ${ }^{35}$ (le diocèse), on lit : "Accipe annulum fidei scilicet signaculum quatinus sponsam Dei, sanctam videlicet ecclesiam, intemerata fide ordinatus illibate custodias ${ }^{36}$. Ici, il s'agit d'insister, de façon symbolique, sur la foi et la fidélité de l'évêque dans sa mission envers son Église.

Dans ce rapide panorama de l'euchologie, il faut accorder une place à part aux prières du canon de la messe. Plusieurs d'entre elles mentionnent la foi dans le double sens d'orthodoxie - ce qui est conforme au dogme de l'Église - et de foi vécue à titre personnel ainsi que de manière communautaire : «Memento, Domine, famulorum famularumque tuarum et omnium circum adstantium, quorum tibi fides cognita est et nota devotio, qui tibi offerunt $[\ldots]^{37}$; Memento etiam domine famulorum famularumque tuarum ill. et ill. qui nos pracesserunt cum signo fidei et dormiunt in somno pacis $[\ldots] \gg^{38}$.

Dans la pratique liturgique et les textes normatifs qui la définissent, liée aux sacrements, on rencontre, parmi les textes spécifiques à tel ou tel rite,

32. Cf. A. Blaise, Le vocabulaire latin des principaux thèmes liturgiques, Turnhout, 1966. pp. $153-155$ et $598-602$.

33. Sur l'histoire de la formule «Fides Ecclesiae», voir les références aux travaux de M.-T. NADEAU, cités à la note 13 .

34. Cf. M.-T. NAdEAU, ibid., pp. 103-105 et $L$ 'ordinaire de la messe, texte critique, traduction et études par B. BotTe. C. MohrmanN, «Études liturgiques 2 », Paris-Louvain, 1953, pp. 8889.

35. J. GaudEMET, "Note sur le symbolisme médiéval. Le mariage de l'évêque », La société ecclésiastique dans l'Occident médiéval, "Variorum Reprints », Londres, 1980, n"X.

36. Voir le texte de la prière et la description du rite de la remise de l'anneau lors de la consécration épiscopale dans le pontifical romain du $12^{\circ}$ siècle, $\mathrm{M}$. AndriEu, Le pontifical romain au Moyen Age, t. I, Le pontifical romain du XII" siècle, "Studi e Testi 86 ", Cité du Vatican, 1938, p. $138 \mathrm{ss}$, p. 162.

37. Le canon de la messe romaine, édition critique, introduction et notes par B. BotTE, «Textes et études liturgiques 2 », Abbaye du Mont César-Louvain, 1935, pp. 32-34.

38. lbid. p. 44. 
en dehors des oraisons même, des paroles prononcées par les acteurs de la cérémonie qui apparaissent comme de véritables affirmations de foi. Dans la liturgie baptismale, cet aspect est particulièrement présent. Déjà dans la prétendue «Tradition Apostolique », au chapitre « De ceux qui vont recevoir le baptême ", on lit : "Quand approche le jour où ils vont être baptisés, l'évêque exorcisera chacun d'eux pour savoir s'il est pur. Si quelqu'un n'est pas bon ou n'est pas pur, on l'écartera, parce qu'il n'a pas entendu la parole avec foi, car il est impossible que l'Étranger se dérobe toujours $\gg^{39}$. Il faut dire que, dans la théologie de l'Eglise, le baptême est par excellence le sacrement de la foi : "sacramentum fidei $»^{40}$. Au cour de la célébration du baptême, cela dès les premiers siècles ${ }^{41}$, il y a la confession de foi, exprimée par la triple interrogation du célébrant à laquelle correspond la triple confession du néophyte. Accompagnant chacune des réponses, on procède à une triple immersion afin d'inclure la foi dans la conception trinitaire. L'introduction en Gaule, dès le $8^{\mathrm{e}}$ siècle, de la formule «Et Ego te baptizo » dite par le prêtre ${ }^{42}$ eut des répercussions sur une modification du rite lui-même : l'acte central du baptême n'est plus l'acte de foi des baptisés mais la parole du prêtre qui l'accompagne. Ce changement intervenu dans la formule baptismale relève du problème global de la compréhension et, d'une certaine manière, de la participation des fidèles à des rites avec lesquels on leur demande d'affirmer leur foi. A propos du baptême, on en est arrivé, dès le $8^{\mathrm{e}}-9^{\mathrm{e}}$ siècle, à considérer la formule du prêtre et elle seule, comme condition de validité sine qua non du sacrement, tandis que la triple profession de foi du baptisé passait au second plan. Une évolution relativement analogue est perceptible dans les conditions requises, aux $12^{\mathrm{c}}$ et $13^{\mathrm{c}}$ siècles, pour que le sacrement de mariage soit valide. Si le baptisé souhaitant se marier a abandonné la pratique de la foi, les théologiens et canonistes affirment qu'il a cependant conservé le sacrement de la foi et c'est cela qui importe. Dès lors, le mariage est considéré comme valide si les époux ont l'intention de faire ce que fait l'Église; ce qui rend impossible l'union sacramentelle, c'est la qualité d'infidèle, d'hérétique, de l'un des conjoints ${ }^{43}$.

Dans la tradition liturgique médiévale, le débat sur l'affirmation de la foi par les fidèles et leur connaissance de celle-ci s'est essentiellement focalisé autour du Credo. Ce n'est en aucun cas l'objet de cette contribution

39. Tradition apostolique, op. cit., p. 79.

40. Voir, sur cette thématique, l'important développement de Thertulilis, Traité sur le baptême, texte, introduction et notes de R. F. RFFOLLÉ, « Sources chrétiennes 35 », Paris, 1952, pp. 45-53.

41. Cf. B. Bobrinskoy, "Confession de foi trinitaire et consécrations baptismales et eucharistiques dans les premiers siècles ", La liturgie, expression de la foi, citée à la note 17, pp. 57-67.

42. Sur l'histoire et le sens de la formule, P.-M. GY, «La formule "Je te baptise" (Et ego te haptizo) ", Communio sanctorum. Mélanges offerts à J.-J. von Allmen. Genève, 1982, pp. 6572 et P. DE CLERCK. «Les origines de la formule baptismale», Rituels. Mélanges offerts au père Gy, Paris, 1990, pp. 199-213.

43. P.-M. GY, "Le sacrement de mariage exige-t-il la foi ? La position médiévale », Revue des Sciences philosophiques et théologiques, 61, 1977, pp. 437-442. 
que de retracer l'histoire de cette prière, en réalité il en existe plusieurs formes, d'un genre si particulier ${ }^{44}$. Contentons-nous simplement de rappeler qu'à partir du $9^{c}$ siècle elle devint, en compagnie du Pater, la connaissance minimale exigée par le clergé auprès des fidèles. Le credo fut rapidement adopté par le clergé, cela dès le $9^{\mathrm{e}}$ siècle mais de manière encore plus forte à Latran IV, comme l'instrument de contrôle privilégié de la foi «implicite » des laïcs. Nombreuses sont les mentions des capitulaires épiscopaux de l'époque carolingienne dans lesquelles l'on exige la connaissance et la signification de la prière tant pour les fidèles que pour le prêtre, car il doit être lui-même l'exemple de la foi ${ }^{45}$. Dans un canon du concile de Mayence (813) au cours duquel on chercha à définir l'idéologie de l'Empire, on rappelle : «Que la paix et la concorde, ainsi que l'unité règnent, de même que nous avons un Père, une Mère l'Église, une foi, un baptême ${ }^{46}$, complété par le canon 45: «Que les prêtres incitent continuellement le peuple chrétien à apprendre le symbole qui est le signe de la foi ainsi que l'oraison dominicale. Nous voulons que ceux qui négligeraient d'apprendre ces paroles soient frappés de la peine qui convient, soit d'un jeûne, soit d'un autre châtiment ${ }^{47}$. Aux yeux des clercs, la foi chrétienne repose bel et bien sur ces deux formules liturgiques, le Credo et le Pater ${ }^{48}$. La règle

44. Pour un résumé de l'histoire du Credo, cf. J.-C. SchmitT, Faire croire..., op. cit., et F. BoESPFLuG, "Autour de la tradition picturale du Credo au Moyen Age (XII'-XV" siècle)", Rituels..., citée à la note 42, pp. 55-84. J. N. D. Kelly, Early Christian Creeds, 1950.

45. G. Devallly, «La pastorale en Gaule au IX ${ }^{\mathrm{e}}$ siècle », Revue d'Histoire de l'Église de France, LIX, 1973, pp. 23-54; sur les mentions concernant le Credo dans les capitulaires épiscopaux, voir les textes édités dans Capitula Episcoporum, I. MGH, P. Brommer (éd.), Hanovre, 1984, par exemple le chap. I du capitulaire de Gautier d'Orléans de 869-870: "Ut archidiaconi per sibi commissas parrechias diligenter discutiant presbiterorum fidem, baptisma et missarum celebrationem, quatinus rectam fidem teneant, baptisma catholicum observent et missarum preces bene intelligant, psalmos digne secundum divisiones versuum modulentur et dominicam orationem cum symbolo et fide catholica ipsi intelligant et omnibus bene pronunciare diebus feriatis insinuent ad intelligendum, ut sciat unusquisque, quid petat ad deum; et ut "Gloria patri et filio et spiritui sancto" et "Credo in unum deum " apud omnes ad missam decantetur et, ut ipse sacerdos cum sanctis angelis et populo dei una voce "Sanctus, sanctus, sanctus" ad missam decantet ", p. 187 ; J. CHÉLINI, L'Aube du Moyen Age. Naissance de la chrétienté occidentale, Paris, 1991, p. 413 ; M. BANNIARD, Viva voce. Communication écrite et communication orale du IV au IX siècle en Occident latin, "Collection des études augustiniennes », Paris, 1992, pp. 211-213,353 et 370-375 et A. DiERKENS, « La christianisation des campagnes de l'Empire de Louis le Pieux. L'exemple du diocèse de Liège sous l'épiscopat de Walcaud (c. 809-c. 831) », Charlemagne's Heir. New Perspectives on the Reign of Louis the Pious (814-840), Oxford, 1990, pp. 311-329.

46. MGH, Concilia II, pars I', Hanovre-Leipzig, 1906, p. 261.

47. Ibid., p. 254, cité d'après la traduction dans Prier au Moyen Age, pratiques et expériences ( $V^{e}-X V^{e}$ siècles), Turnhout, 1991, p. 170.

48. "Commonendi sunt fideles, ut generaliter omnes a minimo usque ad maximum orationem dominicam et symbolum discant. Et dicendum eis, quod in his duabus sententiis omne fidei christianae fundamentum incumbit. Et nisi qui has duas sententias et memoriter tenuerit et ex toto corde crediderit et in oratione saepissime frequentaverit, catholicus esse non poterit. Constitutum namque est, ut nullus chrismetur neque baptizetur neque a lavacro fontis alium suscipiat neque coram episcopo ad confirmandum quemlibet teneat, nisi symbolum et orationem dominicam memoriter tenuerit exceptis his, quos ad loquendum aetas minime perduxit ", extrait du premier capitulaire de ThÉODULF D'OrLÉANS, Capitulare, citée à la note 45, p. 119 ; voir 
énoncée par les capitulaires carolingiens fut plus vigoureuse encore au $13^{\mathrm{c}}$ siècle, notamment après Latran IV, comme en témoignent les mentions tirées des statuts synodaux ${ }^{49}$. A ce moment, outre le "Notre-Père », on associe au Credo le « Je vous salue Marie ». Cette radicalisation du contrôle de la foi chez les fidèles trouve une explication dans le fait que la paroisse n'est plus seulement un centre de rassemblement de fidèles, elle devient un observatoire privilégié des mœurs et de la foi des personnes ${ }^{50}$. Dans certains passages des statuts synodaux, les formules employées ne laissent pas de doute sur les intentions «dominatrices» du clergé. La foi est essentielle pour préserver l'unité de l'Ecclesia mais elle ne doit pas faire l'objet d'une connaissance approfondie de la part des fidèles.

«De l'instruction des fidèles »: De la foi en la Sainte-Trinité. Les prêtres doivent avoir soin d'instruire diligemment les gens, qu'ils soient majeurs ou mineurs, dans la croyance en la Trinité et en l'Incarnation et dans les sept sacrements et dans les sept œuvres de miséricorde qui s'opposent aux sept péchés capitaux. Ils sont tenus d'enseigner expressément au sujet de la Trinité au moins que le Père, le Fils et le Saint-Esprit sont trois personnes et que ces trois personnes sont un seul Dieu et que chacune est distincte des autres, mais, comme la foi n'est pas soumise à la raison, on n'a pas à demander le pourquoi et le comment des choses qui regardent la foi, mais simplement nous devons les croire et dans la vie future nous les comprendrons pleinement.

«Des articles de foi »: Il faut dire souvent aux laïcs qu'ils ne recherchent pas la raison des articles de foi ni des sacrements parce que, si grande est la sublimité de la foi, les choses qui sont au fond ne peuvent être saisies par l'intelligence ; et en conséquence «la foi n'a pas de mérite si elle se fonde sur l'expérience et la raison humaine » (citation de Grégoire le Grand). Qu'on croie donc fermement sans hésitation tout ce que la foi catholique affirme, même si on ne le comprend pas, apportant une créance plus grande aux témoins de la foi qu'aux yeux de chair qui peuvent tromper ${ }^{51}$.

l'interprétation de ce texte dans Prier au Moyen Age, p. 171. Au 14 ${ }^{\mathrm{e}}$ siècle à Montaillou, le "Notre Père » est souvent la seule prière que les paysans du village connaissaient, E. LE RoY LADURIE, Montaillou, village occitan de 1294 à 1324, édition revue et corrigée, Paris, 1982, pp. 476-477 (Pour une critique liturgico-pastorale de ce livre, cf. P.-M. GY, « Montaillou et la pastorale sacramentelle ", La Maison-Dieu, 125, 1976, pp. 127-133).

49. Cf. J. LONGĖRE, « Comment expliquer le symbole des apôtres? L'apport de quelques conciles et synodes médiévaux », Pensée, image et communication en Europe médiévale. A propos des stalles de Saint-Claude, Besançon, 1993, pp. 165-170, dans ce même volume, voir aussi les contributions de B.-G. GUYOT, «L'attribution des articles de foi aux apôtres dans la littérature pastorale latine des XIII"-XIV" siècles », pp. 179-184 et de F. BOESPFLUG, "Symboles de foi et apôtres au Credo. Quelques réflexions sur les fonctions respectives », pp. 257-262.

50. R. FOREvILLE, «Les statuts synodaux et le renouveau pastoral du XIII ${ }^{\mathrm{e}}$ siècle dans le Midi de la France », Cahiers de Fanjeaux, 6, 1971, pp. 119-150. Cf. aussi P.-M. GY, «Évangélisation et sacrements au Moyen Age », Humanisme et foi chrétienne. Mélanges scientifiques du centenaire de l'Institut Catholique de Paris, Paris, 1976, pp. 565-572.

51. O. Pontal, Les statuts synodaux français du XIII siècle précédés de l'historique du synode diocésain depuis ses origines, t. I, Les statuts de Paris et le synodal de l'Ouest (XIII" siècle), "Collection de documents inédits sur l'histoire de France - section de philologie et d'histoire jusqu'à 1610, vol. 9 », Paris, 1971, pp. 226-229 et 234-235. 
La connaissance religieuse minimale des fidèles a entraîné des problèmes théologiques majeurs concernant l'adhésion des fidèles à la foi. Les réponses apportées par les théologiens à ces problèmes ont débouché sur un effort d'évangélisation, surtout aux $12^{\mathrm{e}}$ et $13^{\mathrm{e}}$ siècles, consistant à faire apprendre par cour des formules ou des gestes, tels que le signe de croix, sans forcément exiger leur compréhension par les "simples laïcs » ${ }^{52}$.

Après avoir vu la façon dont les textes liturgiques officiels et les pratiques normatives (ce qui devrait être fait) reflétaient l'expression de la foi, vue à travers les textes de l'Église, penchons-nous sur les indices du témoignage vécu de la transmission de la foi, grâce à d'autres textes, principalement hagiographiques, sortes de dérivatifs pour exprimer «le sensible » de la liturgie que n'expriment pas les textes officiels, plutôt concentrés sur la définition de l'orthodoxie et exprimant le désir de l'Église d'imposer l'unité et l'hégémonie chrétienne.

\section{Modèles de foi, modèles liturgiques dans les vies de saints et autres textes : une autre forme de médiation liturgique}

Dans les textes liturgiques et dans ceux relevant plutôt de la pratique, ou au moins sa norme, on décèle à grand peine la réception par les fidèles de la transmission de la foi, alors que les intentions de l'Église sont claires. Le « vécu » sensible de la foi est pour ainsi dire absent des textes, de nature «juridique » (ou plutôt canonico-liturgique), qui émanent des autorités de l'Église. Ce que l'on perçoit, ce sont les visées dogmatiques et sociales de l'institution ecclésiastique. Depuis peu, les historiens tentent d'approcher la dimension émotionnelle et le sensible des hommes et des femmes du Moyen Age présents dans diverses activités de leur vie. Ainsi, on peut se risquer à une approche du «vécu liturgique » des fidèles et de leur réception de la foi grâce à un regard neuf jeté sur des passages de textes variés, en particulier des vies de saints, des chroniques, des récits de miracles... ; bref, toute une série de textes où la dimension sensible de la liturgie semble s'être exprimée à défaut de pouvoir le faire dans les Écrits (textes sacrés et normatifs) officiels de l'Église.

Dans le christianisme ancien, certaines vies de saints déjà mais également des témoignages de prédicateurs fournissent des renseignements sur les réactions des fidèles lors de l'écoute de la Parole de Dieu, ou de son commentaire. A diverses reprises, saint Augustin s'aperçoit des sentiments manifestés par les gens qui viennent l'écouter ${ }^{53}$. Le caractère nouveau du christianisme médiéval, devenu l'idéologie dominante de la société, amène à produire des textes officiels, émanant du clergé, où cette dimension vécue de la foi tend à se faire plus rare. Il faut donc aller glaner ailleurs que dans

52. Cf. P.-M. GY, «Évangélisation... », art. cité.

53. A. Olivar, "Les réactions émotionnelles des fidèles pendant la lecture solennelle de l'Écriture, dans l'Église des Pères ", Mens concordet voci pour Mgr A.G. Martimort, Paris, 1983, pp. $452-457$, p. 453. 
les textes liturgiques et normatifs les reflets de ce vécu sensible de la liturgie, de la transmission et de la réception de la foi : dans les vies de saints, les chroniques, les vies de grands personnages, des correspondances...

Évidemment ces textes, appartenant à des genres littéraires différents, émanent des milieux ecclésiastiques et sont souvent destinés à l'élite sociale que représentent les souverains, les princes, les nobles, entre autres. En ce sens, si notre hypothèse est juste, on peut considérer les passages de ces textes où il est question de la dimension sensible de la liturgie comme des «modèles » de prières, d'attitudes rituelles élaborées par le clergé et montrant aux couches supérieures de la société la manière de recevoir la foi et de la faire vivre, à l'instar des saints, par exemple, véritables modèles de vie chrétienne et de foi.

Au $9^{\mathrm{e}}$ siècle, dans le Manuel pour mon fils, Dhuoda évoque longuement la nécessité de vivre en faisant croître la foi, l'espérance et la charité, tout en pratiquant assidûment la prière : "Quand tu auras fini, fais un signe de croix sur ton front $[\ldots]$ tout en disant : J'adore ta croix, Seigneur, et je crois en ta sainte résurrection $»^{54}$. A propos de Charlemagne, Eginhard relate qu' « il pratiqua scrupuleusement et avec la plus grande ferveur la religion chrétienne, dont il avait été imbu dès sa plus tendre enfance [...]. Il ne manquait pas, quand il était bien portant, de se rendre à cette église (la basilique de son palais à Aix-la-Chapelle) matin et soir; il y retournait pour l'office de nuit et pour la messe [...]. Il s'employa aussi avec beaucoup de diligence à corriger la façon de "lire " et de psalmodier, étant lui-même très expert en la matière, quoiqu'il ne "lût" point en public et qu'il ne chantât qu'à mi-voix et avec le reste de l'assistance $»^{55}$. A la suite d'Eginhard, l'exaltation des vertus chrétiennes du souverain, en premier lieu la foi, ainsi que celle de sa pratique assidue de la prière, ou de la liturgie au sens large, devint un lieu commun des vies des souverains. Dans sa vie de Robert le Pieux, Helgaud de Fleury écrit :

Fort d'une justice rigoureuse, ce même roi sérénissime s'efforçait de supprimer de sa bouche le mensonge, et au contraire de faire passer avant toute chose la vérité dans son cœur et dans sa bouche, et il jurait assidûment par la foi du Seigneur notre Dieu. Le service du culte faisait ses délices: placé sur terre, il était déjà dans les cieux. Il trouvait sa joie dans les reliques des saints qu'il faisait rehausser d'or et d'argent, dans les vêtements blancs, les ornements sacerdotaux, les croix précieuses, les calices d'or fin,

54. Dhuoda, Manuel pour mon fils, "Sources chrétiennes 225 », Paris, 1975, pp. 122-125 et p. 129 ; P. RiCHÉ, «L'éducation religieuse par les femmes dans le Haut Moyen Age : le manuel de Dhuoda ", La religion de ma mère. Les femmes et la transmission de la foi, J. Delumeau dir., Paris, 1992, pp. 37-49 ; A. McGuire, "Liturgy and Laity in the Ninth Century », Ecclesia Orans, 13, 1996, pp. 463-494. P. GEARY a récémment émis l'hypothèse que, dans son manuel, Dhuoda a cherché avant toute chose à perpétuer la mémoire de la généalogie familiale, La mémoire et l'oubli à la fin du premier millénaire, Paris, 1996, pp. 8485 .

55. Eginhard, Vie de Charlemagne, "Les classiques de l'histoire de France au Moyen Age », L. Halphen (éd. et trad.), Paris, 1967, pp. 76-79. 
les encensoirs qui lancent un encens de choix, les vases d'argent servant aux ablutions du prêtre ${ }^{56}$.

Le modèle du roi chrétien, gouverné par sa foi et la pratique fervente des sacrements et de la liturgie en général, trouva sa parfaite expression en la personne de saint Louis. A son propos, Jacques Le Goff a insisté sur le fait que saint Louis a conjugué l'expression de sa foi chrétienne avec son statut de roi de France ${ }^{57}$. Dans le dossier établi en vue de sa canonisation, on ne rencontre pas moins de 18 chapitres où il est question de l'exercice des trois vertus théologales par le roi $^{58}$; de même que, lors de son couronnement, d'après les ordines de Reims et de 1250, celui-ci prononça quatre serments dont l'un était consacré à la promesse de défendre la foi catholique. Dans l'Histoire de saint Louis, Joinville relate la façon dont saint Louis définissait la foi :

Le roi disait que la foi consistait à croire, même si notre certitude ne reposait que sur un dire. Sur ce point, il me demanda comment mon père s'appelait. Je lui dis que son nom avait été Simon. Il me demanda comment je le savais et je lui répondis que je le croyais fermement et le tenais pour certain parce que ma mère me l'avait dit. Alors, me dit-il, vous devez croire fermement tous les articles de la foi sur le témoignage des apôtres comme vous l'entendez chanter le dimanche au Credo ${ }^{59}$.

Ces vertus de foi, servie par la pratique «liturgique» qui est destinée à la faire grandir, se trouvent aussi exaltées dans des vies de personnalités de l'Église ou bien dans des passages de telle ou telle vie (de souverains par exemple) où l'on insiste sur la piété d'un "simple». Dans la Vie de Gauzlin, André présente à maintes reprises l'abbé de Fleury comme le garant de la foi ( De toutes ces actions si merveilleuses accomplies par cet homme de Dieu, jamais ne furent absentes la foi, l'espérance et la charité ») $)^{60}$ et lui fait dire : "Moi Gauzlin, par la grâce de Dieu d'abord abbé de Fleury puis archevêque de Bourges, j'affirme par ces simples mots devant toutes les preuves de la foi, ceci : je proclame que le Père et le Fils et le Saint-Esprit sont un seul Dieu et je dis que, tout entière dans la Trinité, la divinité est coessentielle $[\ldots] »^{61}$. Gauzlin poursuit par une véritable confession de foi, une sorte de Credo ${ }^{62}$.

56. Helgaud de Fleury, Vie de Robert le Pieux, "Sources d'histoire médiévale 1 », texte édité, traduit et annoté par R.-H. Bautier et G. Labory, Paris, 1965, pp. 76-77 (66-69).

57. J. Le Goff, Saint Louis, Paris, 1996, p. 126, pp. 603-606 (751-753) ; J. Le Goff, P.-M. GY, "Saint Louis et la pratique sacramentelle », La Maison-Dieu, 197, 1994, pp. 99124. Sur la dévotion des rois de France, voir en dernier lieu, B. GuENÉE, " Le vœu de Charles VI. Essai sur la dévotion des rois de France aux XIII' et XIV" siècles ", Journal des savants, 1996, pp. 67-135.

58. J. LE GOFF, op. cit., p. 340.

59. Ibid., p. 751.

60. ANDRÉ DE FleURY, Vie de Gauzlin, abbé de Fleury, "Sources d'histoire médiévale 2 ", texte édité, traduit et annoté par R.-H. Bautier et G. Labory, Paris, 1969, p. 117.

61. Ibid., pp. 99-101.

62. La référence est ici celle des Statuta Ecclesiae Antiquae; il n'est pas rare dans les récits hagiographiques que les saints confessent leur foi avant la mort afin de se présenter pur devant 
Inspirés du modèle des vies de saints, certains textes établissent une relation directe entre la pratique «liturgique » (souvent on ne mentionne que la prière ou bien la méditation des psaumes par exemple), les manifestations divines ou miraculeuses et, souvent il ne s'agit que d'une allusion implicite, la force de la foi. Dans le long poème composé en 826 à la gloire de Louis le Pieux, Ermold le Noir rapporte que Theutrammus, gardien de l'église Notre-Dame de Strasbourg, passait souvent le jour et la nuit en prière devant l'autel de la Vierge et, poursuit-il, «c'est pourquoi, favorisé de la grâce divine, le saint homme mérita souvent d'apercevoir les anges ${ }^{6.3}$; d'autres visions s'ensuivirent. Pierre Damien relate l'histoire d'un clerc qui, pour satisfaire sa propre dévotion privée, disait chaque jour l'Ave Maria devant l'autel de la Vierge. A la suite de cette pratique assidue, la Vierge apparut au clerc et lui demanda de faire dire plusieurs messes spéciales en son honneur et en celui des anges et de tous les saints, selon un rythme hebdomadaire bien précis ${ }^{64}$. Ces textes, on s'en rend compte, comblent sur le versant sensible du vécu «liturgique » les insuffisances sur ce point précis des textes liturgiques officiels et des décisions normatives. Ici, on veut signifier que celui qui prie avec ferveur et dévotion ne peut que voir sa foi grandir en lui jusqu'à le rendre témoin de visions et de miracles. $\mathrm{Ce}$ modèle de prière et de foi se rencontre fréquemment dans les vies de saints, comme par exemple dans le sermon sur sainte Maure de Troyes, composé par Prudence de Troyes $(\dagger 861)$ vraisemblablement entre $843 / 845$ et $861^{65}$. Dans ce texte, l'auteur décrit trois images (une Vierge à l'Enfant, la crucifixion, et une représentation de Dieu en majesté) qui se trouvaient dans la crypte de la cathédrale de Troyes et avaient suscité de la part de la sainte une dévotion particulière, modèle à imiter par les contemporains. La dévotion incessante de la sainte envers ces images provoqua des manifestations miraculeuses. "J'ai fréquemment entendu, dit la sainte, et l'enfant qui vagissait sur les genoux de sa mère et le jeune homme qui gémissait sur la croix et le roi terrestre qui tonnait sur son trône mais qui me donnait amicalement un sceptre d'or », et d'invoquer d'elle-même les raisons de ces «cris », elle poursuit : "Ce n'est pas au domaine de la nature mais à celui des miracles que l'on doit d'attribuer le fait que pour rappeler à notre foi les sacrements merveilleux et les affermir dans l'esprit des fidèles un bois sec émette un vagissement ou un gémissement ${ }^{66}$. Le message est clair : la foi et (par) les sacrements doivent grandir en chacun de nous et,

Dieu, cf. P. HenRIET, "Silentium usque ad mortem servaret. La scène de la mort chez les ermites italiens du XI $\mathrm{X}^{\mathrm{e}}$ siècle ", Mélanges de l'École française de Rome, 105, 1993, pp. 265298 (pp. 290-292) ; je remercie D. Iogna-Prat d'avoir attiré mon attention sur ce point.

63. ERmold le NoIr, Poème sur Louis le Pieux et épîtres au roi Pépin, "Les classiques de l'histoire de France au Moyen Age », édités et traduits par E. FARAL, Paris, 1964, pp. 192193.

64. PL. 145, col. 564-565.

65. A. CASTES, «La dévotion privée et l'art à l'époque carolingienne : le cas de sainte Maure de Troyes », Cahiers de Civilisation médiévale, 33, 1990, pp. 3-18. Je n'ignore pas la contestation faite quant à la date de ce texte, mais je laisse à d'autres le soin de régler cette question.

66. Ibid., pp. 3-4. 
pour cela, seuls les miracles sont nécessaires, miracles rendus possibles par la pratique dévotionnelle. L'efficacité de la prière liturgique, dans sa dimension à la fois intérieure et extérieure (les gestes, le langage), pour l'affermissement de la foi s'avère directement perceptible. En ce sens, le texte de Prudence de Troyes anticipe sur les développements ultérieurs à propos de la qualité intérieure de la dévotion et de la prière, telle que la définira, par exemple, Robert d'Arbrissel dans une lettre à la comtesse Ermengarde :

Il écrit aussi : lorsque vous voudrez prier, entrez dans votre chambre, fermez la porte et priez votre Père ; et votre Père, qui voit tout ce qui est caché, vous récompensera. Une courte prière est toujours utile. C'est la prière du cœur et non celle des lèvres qui est agréable à Dieu. Dieu ne fait pas attention aux paroles, mais au cœur de celui qui prie. Toutes les bonnes œuvres des justes sont des prières. Nous pouvons toujours prier de cœur, et pas toujours de bouche. Il est écrit dans l'Évangile: ne parlez pas beaucoup en priant, comme les païens qui croient en criant bien haut se faire entendre de leurs idoles. Quand vous priez votre Père, dites-lui : Notre Père qui êtes aux cieux. Conservez toujours cette oraison dominicale dans votre mémoire et dans votre cœur. Comme vous avez beaucoup d'affaires qui vous occupent, faites des prières courtes ${ }^{67}$.

Pour conclure cette partie, insistons à nouveau sur le modèle idéal que représente le saint aux yeux du chrétien, cela pendant tout le Moyen Age, notamment pour tout ce qui touche à la pratique « liturgique » et dévotionnelle dans le but d'affirmer sa foi. Comme l'a récemment montré JeanMarie Sansterre à propos du Mont-Cassin au $11^{\mathrm{e}}$ siècle, l'érémitisme « aurait représenté [...] l'idéal de la vie religieuse par la rigueur de ses exigences ainsi qu'un moyen d'élever le niveau des comportements chrétiens de la population en général en lui proposant un modèle auquel tout chrétien devait aspirer ${ }^{68}$. A l'appui de son hypothèse, l'auteur cite le chapitre final de la vie de l'ermite Mennas ( $6^{\mathrm{e}}$ siècle), écrite en 1094 : «Vénérons donc, très chers, avec un cœur plein de dévotion ce sénateur si remarquable de la curie céleste, veillons en y disposant tout à fait notre esprit à imiter ses exemples autant que le permet notre fragilité. En effet, si nous désirons parvenir là où il est parvenu, il nous est également nécessaire d'avancer par le chemin où il s'est avancé et de suivre sur la route les traces de celui dont nous souhaitons avoir la compagnie dans la patrie (céleste) ${ }^{69}$. Cette

67. J. de PÉtignY, «Lettre inédite de Robert d'Arbrissel à la comtesse Ermengarde », Bibliothèque de l'école des Chartes, XV, 1854, pp. 209-235 (pp. 232-233) ; G. Constable, «The Concern for Sincerity and Understanding in Liturgical Prayer, Especially in the Twelfth Century », Classica Mediaevalia : Studies in Honor of Joseph Szvövérffy, Washington, 1986, pp. $17-30$ (p. 26).

68. J. M. SANSTERRE, «Recherches sur les ermites du Mont-Cassin et l'érémitisme dans l'hagiographie cassinienne », Hagiographica, II, 1995, pp. 57-92 (p. 69).

69. Ibid., p. 71. Dans les vies de saints illustrés du Moyen Age, on assiste souvent à des transformations iconographiques, par rapport au message initial du texte, qui relèvent d'adaptations aux mentalités de l'époque où l'on a réalisé tel ou tel manuscrit; voir par exemple le cas de l'illustration de la vie de saint Aubin, du $11^{\mathrm{e}}$ siècle, M. Carrasco, «Notes on the 
vie, comme certainement bien d'autres, était destinée à être lue devant un public de laïcs. On peut cependant se demander ce qu'il en était de la compréhension effective du message et des suites réelles sur le comportement des fidèles. A vrai dire, nous sommes assez démunis pour les apprécier. Il est plus aisé en revanche de distinguer les différents destinataires de ces messages. Certains de ces textes, nous l'avons déjà évoqué, circulaient uniquement parmi les personnes lettrées appartenant à l'élite sociale. Pour le peuple, la réception du message est plus incertaine. Doiton alors imaginer la transmission de ce même message, quant à la pratique liturgique et la foi, par l'intermédiaire (ou en complément de l'Écrit) des images?

\section{La foi et la médiation liturgique des images}

Parmi la foisonnante richesse de l'iconographie médiévale, je distinguerai trois types d'images dans lesquels s'exprime le rapport à la foi. Premièrement, il y a le cas des images où le thème iconographique n'illustre pas explicitement une prise de position sur la foi, mais dont on sait, grâce aux textes décrivant les pratiques dévotionnelles qui accompagnent ces images, qu'elles étaient au cœur de la transmission de la foi. Deuxièmement, il existe des images à caractère proprement dogmatique, où le rapport à la foi, par telle ou telle pratique liturgique figurée, se trouve exprimé. Enfin, et c'est par elles que je commencerai, on rencontre des représentations d'épisodes bibliques ou tirées de textes divers - là encore bon nombre appartiennent au genre hagiographique - où le sujet du récit tourne autour de la foi, de sa connaissance et de sa perception par les protagonistes de l'histoire. Dans chaque cas se pose la délicate question des destinataires des images et de leur réception effective ; j'y reviendrai en conclusion.

Nombre de récits évangéliques évoquent des moments de la vie du Christ au cours desquels il a dû éprouver la foi de ses proches. Certains de ces passages ont donné lieu à une illustration, rencontrée fréquemment dans les livres d'Évangiles enluminés, où les artistes se sont attachés à opposer l'expression confiante du Christ avec celle apeurée des personnages de l'histoire. C'est le cas, par exemple, pour l'illustration de la péricope dans laquelle le Christ apaise la tempête (Mc, IV, 35-41), marquée par son exclamation finale adressée aux apôtres: "Pourquoi avez-vous si peur ? Vous n'avez pas encore de foi ? ». Dans les images, les artistes ont montré la peur des apôtres ou plutôt leur absence de foi ${ }^{70}$, comme dans la splendide miniature des Évangiles ottoniens d'Hitda réalisé à Cologne, en gravant l'expression de l'incrédulité sur les visages des disciples ${ }^{71}$. La traduction

Iconography of the Romanesque Illustrated Manuscript of the Life of St. Albinus of Angers ", Zeitschrift für Kunstgeschichte, 47, 1984, pp. 333-348.

70. Je ne connais pour ma part aucune affectation liturgique de cette péricope au Moyen Age.

71. Darmstadt, Hessische Landesbibliothek, cod. 1640, L. Grodecki, F. Mütherich, J. Taralon, F. Wormai.d, Le siècle de l'an mil, Paris, "L'univers des formes », 1973, fig. 146. 
iconographique de l'épreuve de la foi (ou de l'incrédulité) se rencontre sous des formes différentes dans d'autres exemples. Dans la compilation latine du Protévangile de Jacques élaborée aux $6^{\mathrm{c}}-7^{\mathrm{e}}$ siècles, le PseudoMatthieu raconte qu'au moment de la Nativité étaient présentes deux femmes, des sages-femmes, dont l'une, Salomé, ne croyant pas à l'enfantement virginal, voulut toucher la Vierge. Comme la Vierge le lui avait permis, Salomé avança sa main pour toucher Marie, mais tandis qu'elle la touchait, sa main se dessécha. Effrayée par ce qui lui arrivait à cause de son incrédulité, la sage-femme reconnut son erreur et implora le Seigneur. Un ange lui apparut et lui demanda de toucher l'Enfant Jésus. Ce geste eut pour effet de guérir sa main. Analysant les expressions iconographiques de la virginité de la Mère de Dieu, Hélène Toubert a présenté plusieurs images, principalement des ivoires du Haut Moyen Age, où l'on voit clairement la main desséchée de Salomé ${ }^{72}$. Par la suite, dès le $11^{\mathrm{e}}$ siècle, la transposition de cet épisode en drame liturgique fera passer au second plan l'incrédulité de Salomé et sa traduction iconographique. Citons enfin, dans cette même catégorie d'images, la fresque de San Clemente à Rome qui illustre le passage de la Passion romaine où nous est raconté comment Sisinnius, ami de l'empereur Néron, curieux et jaloux en voyant sa femme Theodora quitter leur maison, la suivit malgré elle et pénétra dans le lieu où saint Clément était en train de célébrer la messe ${ }^{73}$. L'image montre Sisinnus, à côté de l'autel sur lequel Clément officie, devenu sourd et aveugle à cause de ses soupçons, supporté par ses esclaves. Grâce aux prières de sa femme, il recouvra les sens.

Les exemples affluent pour illustrer le cas des images qui appartiennent à la première catégorie que $\mathrm{j}$ 'ai définie ${ }^{74}$. Je ne parlerai ici que des images de dévotion, fortement marquées par leur fonction auprès des fidèles. Bien souvent ces images suscitent un véritable culte qui se focalise autour de l'objet lui-même. On observe ce phénomène en particulier pour les statuesreliquaires et les icônes, investies de pouvoir surnaturel. Je n'insisterai pas sur les manifestations physiques des statues (de la Vierge à l'Enfant et de la crucifixion) auprès desquelles sainte Maure de Troyes aimait $\operatorname{prier}^{75}$; on a déjà noté plus haut la place tenue par ses manifestations dans l'acquisition de la foi par la sainte. D'autres récits, n'appartenant pas forcément au même genre littéraire hagiographique, relatent la forte impression produite sur le fidèle par des statues, véritables idoles christianisées, l'aidant à prier et à faire croître sa foi. Ces récits jouaient vraisemblablement un rôle dans

72. H. Toubert, « La Vierge et les sages-femmes. Un jeu iconographique entre les Évangiles apocryphes et le drame liturgique ", Marie. Le culte de la Vierge dans la société médiévale, Paris, 1996, pp. 327-360 qui présente également le dossier textuel du récit dont l'allusion à l'incrédulité de Thomas (Jean, XX, 25) est évidente.

73. Cf. H. TOUBERT, "Rome et le Mont-Cassin : nouvelles remarques sur les fresques de l'église inférieure de Saint-Clément de Rome », Un art dirigé. Réforme grégorienne et iconographie, Paris, 1990, pp. 193-238, pp. 205-208.

74. H. Belting, Bild und Kult. Eine Geschichte des Bildes vor dem Zeitalter der Kunst, Munich, 1990.

75. Cf. A. Castes, "La dévotion privée... », art. cité. 
l'incitation à la prière visant à la réception et à l'expression de la foi chez les fidèles. Le culte mis en place autour de la statue-reliquaire de sainte Foy de Conques illustre à merveille cette tendance ${ }^{76}$. La statue de sainte Foy, objet d'un culte pluriforme, produisit auprès des contemporains une impression si forte - dans son livre des Miracles, écrit entre 1007 et 1029 environ, Bernard d'Angers raconte même qu'elle fixait du regard les fidèles ${ }^{77}$ - qu'elle fut à l'origine d'un nombre impressionnant de conversions et de miracles. A ce propos, Jean Wirth a parlé de manière pertinente du thème paulinien de la foi par l'écoute $\left(\mathrm{Rm}\right.$. X, 17) ${ }^{78}$. D'autres récits tournant autour de la dévotion à la croix et au crucifix débouchent sur des conséquences identiques en matière d'expression de la foi à celles observées pour la statue de sainte Foy. Devenue une source de stimulation spirituelle, la dévotion à la croix et au crucifix prit de multiples formes tout au long du Moyen Age $^{79}$. Considéré comme le trophée de la victoire du Seigneur, directement construit par la foi, le crucifix - l'image du Christ souffrant crucifié - devint une image d'adoration, de vénération, sur laquelle se focalise la foi du croyant. Dans le livre de prières de Charles le Chauve (Munich, Schatzkammer der Residenz, ff. 38v.-39r.), on a représenté le souverain agenouillé - ne pourrait-on dire en prière ? - devant l'image du Christ sur la croix ${ }^{80}$. Dans le texte carolingien de Prudence de Troyes, la sainte prie devant un crucifix qui lui répond par des gémissements. Dans l'une de ses lettres, Pierre le Vénérable, abbé de Cluny entre 1122 et 1156 , nous a laissé un témoignage sur sa mère, au moment de sa mort :

Alors, ointe de l'huile sainte à sa demande, restaurée pour l'éternité par le corps du Christ, abritée par son humilité et rassurée par son aveu, elle demanda qu'on lui présentât la croix avec l'image du Seigneur. Tandis que la croix est apportée, des plaintes redoublées parcourent le monastère. Elle porte à ses lèvres l'image de son Seigneur, de sa langue elle lui lèche les pieds, et elle l'étreint sur son visage de toute la force de son corps. Elle adore la Passion du Sauveur, et par sa mort et ses blessures, elle l'adjure de lui donner le salut. Devant tous les assistants, elle confesse que nulle gloire, nulle espérance de salut ne subsiste en elle, hors de la croix de son Seigneur. Et tandis qu'elle a achevé sa prière, et que ceux qui l'assistent tentent d'éloigner de son visage l'image du Seigneur, voici qu'elle s'écrie, dans l'ardeur de sa foi : «Pourquoi voulez-vous m'enlever mon Seigneur?

76. Cf. en dernier lieu J.-C. SCHmitT, «Rituels de l'image et récits de vision », Testo $e$ immagine nell'alto Medioevo, XLI Settimana di studio del Centro italiano di studi sull'alto Medioevo, Spoleto 1993, Spolete, 1994, pp. 419-462.

77. Cf. P. K. KLEIN, «Programmes eschatologiques, fonction et réception historiques des portails du XII ${ }^{\mathrm{e}}$ siècle: Moissac, Beaulieu, Saint-Denis », Cahiers de Civilisation médiévale, 33, 1990, pp. 317-349 (pp. 347-348).

78. J. WIRTH, L'image médiévale. Naissance et développements ( $V I^{*}-X V^{e}$ siècle), Paris, 1989 , pp. $171-194$ (p. 183).

79. A. WILMART, «L'office du crucifix contre l'angoisse", Ephemerides Liturgicae, 46, 1932, pp. 421-434 et J. LeCl.ERCQ, "La dévotion médiévale envers le crucifié », La MaisonDieu, 75, 1963, pp. 119-132.

80. R. Deshimann, "The Exalted Servant. The Ruler Theology of the Prayerbook of Charles the Bald », Viator, XI, 1980, pp. 385-417. 
Laissez-moi donc, aussi longtemps que je vis, celui vers qui je vais m'en aller en mourant ». Ce n'est pas l'image du Christ, c'est le Christ lui-même qu'elle croyait voir sur cette croix, et ne pouvait se résoudre à desserrer son étreinte ${ }^{81}$.

Pour Pierre le Vénérable, le geste dévot de sa mère exprime, loin des rites officiels et formalistes de l'Eglise, la grande valeur de la prière d'adoration, à caractère privé et à l'aide d'une image, pour l'expression de la foi ${ }^{82}$. Rappelons que ce texte s'insère dans un ensemble plus vaste de réflexion, par Pierre le Vénérable, sur la valeur du signum (la croix) comme expression sacramentelle de l'eucharistie ${ }^{83}$.

Dans les exemples précédemment cités, la croix - l'image du crucifix - acquiert une valeur apotropaïque. Au même titre qu'une icône, elle est investie d'un pouvoir spirituel directement contenu dans l'objet. Plusieurs études ont démontré, à propos de telle statue, de telle fresque ou de telle icône ${ }^{84}$, la place tenue par ces images apotropaïques - parfois il s'agit de l'image du crucifié - dans la dévotion des fidèles, et j'ajouterai pour ma part, pour la transmission et l'expression de leur foi ${ }^{85}$. L'ancrage social de certaines de ces images ajoute une dimension supplémentaire à leur rôle, déjà fondamental, joué auprès des hommes du Moyen Age. A titre d'exemple, citons le célèbre crucifix du volto santo de Lucques, image achéiropoiète en même temps que statue-reliquaire, dont les manifestations miraculeuses offrent une signification sociale principalement axée sur le

81. Prier au Moyen Age, op. cit., pp. 97-98.

82. Sur le rôle des femmes dans la transmission de la foi d'une manière générale et par les images en particulier, cf. N. BÉRIOU, «Femmes et prédicateurs. La transmission de la foi aux XII" et XIII" siècles", La religion de ma mère..., op. cit., pp. 51-70, D. RIGaUX, "Dire la foi avec les images, une affaire de femmes? », ibid., pp. 71-90.

83. Je dois cette importante précision à Dominique Iogna-Prat que je remercie. L'interprétation de ce texte a été donnée par D. Iogna-Prat, Ordonner et exclure. Cluny et la société chrétienne face à l'hérésie, au judaïsme et à l'lslam, 1000-1150, Paris, 1998, p. 194.

84. Cf. H. Belting, op. cit. , pp. 253-291 ; citons en particulier l'icône de la Vierge qui, à Rome lors de la liturgie de l'Assomption, a joué un rôle fondamental pour la dévotion des fidèles. Récemment, M. EXNER a montré que les fresques, représentant deux crucifixions, de la crypte de Saint-Georges d'Oberzell à Reichenau faisaient office de « reliquaires » comme posés devant des autels, "Die Wandmalereien der Krypta von St. Georg in Oberzell auf der Reichenau », Zeitschrift für Kunstgeschichte, 58, 1995, pp. 153-180. Voir aussi les riches exemples étudiés par J.-M. SANSTERRE, "Vénération et utilisation apotropaique de l'image à Reichenau vers la fin du $10^{\mathrm{c}}$ siècle : un témoignage des Gesta de l'abbé Witigowo », Revue belge de Philologie et d'Histoire, 73, 1995, pp. 281-285, "Un saint récent et son icône dans le Latium médiéval au XI $I^{\mathrm{e}}$ siècle. A propos d'un miracle de Dominique de Sora », Byzantino Slavica, LVI, 1995 (Mélanges offerts à V. Vavrinek), pp. 447-452 et «Le moine ciseleur, la Vierge Marie et son image : un récit d'Ekkehart IV de Saint-Gall », Revue bénédictine, 106, 1996, pp. 185-191.

85. Je me permets de renvoyer à É. PALAZ7o, «Les pratiques liturgiques et dévotionnelles et le décor monumental dans les églises du Moyen Age ", L'emplacement et la fonction des images dans la peinture murale du Moyen Age, Actes du $5^{\mathrm{C}}$ Séminaire international d'art mural, Saint-Savin 1992, Saint-Savin, 1993, pp. 45-56 ; voir aussi D. RusSo, «Les fonctions dévotionnelles de l'image religieuse dans l'Italie médiévale », L'image..., op. cit., n. 3, pp. 133153. 
pouvoir de l'évêque dans la cité lucquoise ${ }^{86}$. Parmi les nombreux miracles dont est crédité le crucifix, relevons celui, de nature cultuelle, qui permet à un jeune homme simple d'apprendre à prier devant l'image et, surtout, l'épisode du jongleur auquel l'image du Christ (la statue-reliquaire) offre son soulier droit, lui exprimant ainsi sa reconnaissance pour l'avoir vénérée à sa manière, c'est-à-dire en jouant de son instrument à défaut de connaître des prières. Il s'ensuivra une interprétation civique de l'événement car l'évêque se verra contraint par le Christ de racheter au jongleur, à l'homme simple, le précieux soulier.

On pourrait multiplier les exemples d'images où la théologie dogmatique, en rapport avec la définition de la foi (et sa transmission), se trouve exprimée. Afin de ne pas alourdir inutilement cette contribution, je ne ferai que présenter, par un rappel succinct, les différents modes d'illustration picturale du Credo et les conclusions de l'analyse d'une image eucharistique contenue dans un livre d'heures du $15^{\mathrm{e}}$ siècle.

Récemment étudiée par François Boespflug et Anne Ritz-Guilbert notamment, la transcription picturale des articles de foi constituant le Credo répond aux nécessités de contextes iconographiques variés ${ }^{87}$. Le début du $14^{\mathrm{c}}$ siècle a vu naître le Credo typologique, faisant correspondre aux douze mois de l'année les douze articles de la profession de foi, eux-mêmes associés aux douze apôtres. On relève pour la première fois cette iconographie typologique particulière dans le bréviaire de Belleville (Paris, BNF, lat. 10483), manuscrit d'usage dominicain et réalisé par Jean Pucelle et son atelier vers 1323-1326. Bien qu'il faille, comme l'a démontré A. RitzGuilbert, faire remonter l'association calendrier-Credo jusqu'aux environs de 1260 , le message de l'illustration du bréviaire de Belleville semble clair : le temps nécessaire à la victoire de la foi sur la synagogue se trouve défini, de sorte que, par la pratique du Credo, le chrétien contribue à la victoire de l'Ecclesia dont il est l'un des membres. F. Boespflug a, pour sa part, bien mis en évidence les autres aspects de la traduction picturale du Credo, ou plutôt des quatre Symboles de foi. Certains, comme le Quicumque ou Symbole d'Athanase, ont seulement fait l'objet d'une transcription iconographique limitée aux aspects événementiels de leur définition - par exemple, la représentation de la réunion du concile - laissant entièrement de côté le contenu de la foi sur lequel les pères conciliaires se sont accordés. A croire que, et ceci intéresse directement notre propos, la transmission par l'image du contenu de la foi s'avère, dans certains cas au moins, pour le moins difficile, voire impossible. En fin de compte, Boespflug constate la richesse iconographique suscitée par le Credo (Symbole des Apôtres) avec ses douze articles de foi. Dès le $9^{e}$ siècle, époque de fixation du texte,

86. J. C. Schmitr, «Cendrillon crucifiée. A propos du Volto santo de Lucques », Miracles, prodiges et merveilles au Moyen Age, XXV" Congrès de la SHMES (Orléans, juin 1994), "Série Histoire ancienne et médiévale-34 », Paris, 1995, pp. 241-269.

87. F. BoespFi.ug, «Symboles de fois... », art. cité n. 49, A. Ritz-Guilbert, «Aspects de l'iconographie du Credo des Apôtres dans l'enluminure médiévale », Pensée, image..., op. cit., pp. $101-110$. 
par exemple dans le psautier d'Utrecht, on illustre le contenu théologique et historique des articles, avant que la correspondance avec les apôtres ne devienne la règle à la suite des miniatures du bréviaire de Belleville. A partir de là, l'illustration du Symbole des Apôtres s'inscrit de façon presque permanente dans le jeu des correspondances typologiques entre l'Ancien et le Nouveau Testament, faisant apparaître les prophètes aux côtés des apôtres associés aux articles du Symbole.

S'inscrivant dans le contexte des nombreuses controverses sur la Présence réelle, cela depuis l'époque carolingienne, l'iconographie de l'Eucharistie reflète pour une large part les positions de l'Église sur l'expression et la transmission de la foi par la célébration de la messe ${ }^{88}$. Je laisse volontairement de côté tout ce qui tourne autour du « désir de voir l'hostie », lié à la pratique de l'élévation de l'hostie à la messe et au débat sur le moment de la transsubstantiation, que les fidèles transformeront en une véritable obsession, frôlant même l'idolâtrie ${ }^{89}$. Je vais succinctement présenter l'iconographie exceptionnelle d'une image contenue dans un livre d'heures. La signification de cette enluminure est considérable pour le sujet qui nous occupe. Réalisées en Autriche aux environs de 1470, les Heures de Johann Siebenhirter (Stockholm, Bibliothèque Royale, ms. A 225) contiennent un cycle illustré de neuf miniatures. L'une d'elle, peinte au folio 158v comme illustration des complies de l'office du Corpus Christi, représente la progression de l'orthodoxie vers l'hérésie. Sous les yeux attentifs d'un évêque, trois prêtres donnent la communion à trois fidèles agenouillés. Sur l'hostie administrée au premier communiant, la figure du Christ se dessine; le deuxième fidèle s'apprête à «avaler» un simple morceau de pain ; et le troisième, quant à lui, voit un crapaud apparaître sur l'hostie qu'on lui tend ${ }^{90}$. Jeffrey Hamburger a bien souligné que cette triple iconographie de l'Eucharistie avait pour but de montrer les trois types de communion possible ${ }^{91}$. Dans la première, le fidèle croit en la transsubstantiation ; dans la deuxième, le doute est présent puisque l'hostie reste à l'état de pain ; tandis que dans la troisième, la dénégation du sacrement mène le personnage à l'hérésie et à une transsubstantiation démoniaque.

88. J. DE MONTCLOS, Lanfranc et Bérenger. La controverse eucharistique du XI siècle, Louvain, 1971 ; pour les implications iconographiques de la controverse dans la production artistique de la région de Tours, M. SCHAPIRO, "Two Romanesque Drawings in Auxerre and Some Iconographic Problems", Studies in Art and Literature for Belle Da Costa Greene, Princeton, 1954, pp. 331-349, H. TouberT, «Dogme et pouvoir dans l'iconographie grégorienne. Les peintures de la Trinité de Vendôme », Un art dirigé..., op. cit., pp. 365-402.

89. E. DuMOUTET, Le désir de voir l'hostie et les origines de la dévotion au Saint-Sacrement, Paris, 1926, M. Dykmans, « Aux origines de l'élévation eucharistique », Zetesis. Album amicorum (Mélanges E. de Strycker), Anvers-Utrecht, 1973, pp. 679-694; pour les transpositions iconographiques de cette pratique, M. RuBIN, Corpus Christi. The Eucharist in Late Medieval Culture, Cambridge, 1991.

90. Allusion à la révélation de la trahison de Judas révélée par le Christ au moment de la Cène : « [...] C'est celui à qui je donnerai la bouchée que je vais tremper. Sur ce, Jésus prit la bouchée qu'il avait trempée et il la donna à Judas Iscariote, fils de Simon. C'est à ce moment, alors qu'il lui avait offert cette bouchée, que Satan entra en Judas » (Jean XIII, 26-27).

91. J. Hamburger, "Bosch's Conjuror: An Attack on Magic and Sacramental Heresy », Simiolus, 14, 1984, pp. 5-23 (pp. 13-14) et fig. 5. 
Pour le fidèle consultant son livre d'heures au moment de la prière, la démonstration était faite, par l'image, du modèle de foi qu'il devait suivre afin de pratiquer une liturgie en accord avec l'orthodoxie ${ }^{92}$.

A l'issue de cet article, la place prééminente de la liturgie au sein des principaux vecteurs de transmission de la foi au Moyen Age a été amplement vérifiée. Il ressort de notre enquête la forte impression de se trouver face à une sorte de triptyque liturgique articulé dont l'objectif essentiel est d'œuvrer pour la transmission de la foi. D'un volet à l'autre de ce triptyque, la réception effective de la foi par les fidèles apparaît perceptible. Le premier volet est constitué par les textes liturgiques à proprement parler, principalement les prières, où s'exprime l'orthodoxie de la foi définie par l'Église. Le deuxième volet comprend les textes normatifs par lesquels les autorités ecclésiastiques tentent d'accorder la pratique liturgique avec le contenu des pièces sacrées. Dans ces deux volets, on voit se profiler les tensions sousjacentes entre les considérations dogmatiques, théologiques, et les velléités du clergé pour accentuer son pouvoir dans la société. Ainsi, le rôle social de la liturgie médiévale, ici en ce qui concerne la transmission de la foi aux fidèles, s'affirme à nouveau. Enfin, le troisième volet de ce triptyque, avec les récits hagiographiques et autres textes ainsi que les images, accueille toute la dimension sensible du «vécu » liturgique, indispensable pour la transmission de la foi. En effet, ces textes et les images proposent des médiations qui leur parlent plus directement que les textes liturgiques. Prenant en compte toutes les composantes de la liturgie (dogmatique, rituelle, sensible), ce triptyque a fonctionné durant tout le Moyen Age afin de transmettre efficacement la foi, du moins aux yeux du clergé.

Nous l'avons déjà dit, la réception effective de la foi par les fidèles demeure difficilement visible. Nous pouvons cependant percevoir les intentions de l'institution ecclésiastique dans la mise en œuvre de la transmission de la foi, selon les destinataires potentiels visés par l'un ou l'autre des volets du triptyque. Les textes sacrés semblent réservés à l'élite cultivée du clergé. Élaborés par les théologiens, ils restent confinés dans les cercles restreints des savants docteurs de l'Église. Les textes normatifs de la pratique, bien que destinés à être appliqués à tous, relèvent encore des hautes sphères du pouvoir ecclésiastique ${ }^{93}$. En revanche, les récits divers et les images, bien qu'élaborés dans leur majorité par des hommes d'Église, visent

92. Sur la dévotion des laïcs à la fin du Moyen Age à partir de livres d'édification illustrés, cf. G. LOBRICHON, "La Bible des pauvres du Vatican, palat. lat. 871. Essai sur l'émergence d'une spiritualité laïque dans l'Allemagne de la fin du Moyen Age », Mélanges de l'École française de Rome, 98, 1986, pp. 295-327.

93. Dans l'Occident médiéval, la diffusion de la foi par les institutions ecclésiastiques a impliqué une participation active, avec des variantes selon les époques et les lieux, aussi bien des religieux que du clergé séculier. Ceci ne semble pas avoir été le cas pour d'autres régions, telle la Russie moscovite entre le $14^{\mathrm{C}}$ et le $16^{\mathrm{e}}$ siècle, où la transmission de la foi a été essentiellement le fait du monachisme, cf. P. GonnEAu, "Monachisme et diffusion de la foi dans la Russie moscovite (14 $14^{\mathrm{e}}-16^{\circ}$ siècle) », Annales HSS, 1996, n" 2, pp. 463-489. 
un public plus large et s'adressent à la dimension sensible des personnes. Les vies de saints, chroniques et autres, étaient lues par les rois et les princes, les nobles et les bourgeois des villes qui pouvaient ainsi s'imprégner des «modèles de foi et de prière » décrits dans ces textes. Et même s'ils n'en percevaient pas toutes les subtilités, au moins connaissaient-ils le message les incitant à être des pratiquants assidus de la prière, cela afin de faire croître en eux la foi. Quant aux images, également «programmées » par les théologiens, elles permettaient d'ouvrir encore plus largement, n'en doutons pas, la transmission de la foi aux simples fidèles. Dans ce domaine du visuel, on distinguera toutefois les images visibles de tous (fresques, sculptures monumentales, statues-reliquaires, icônes...) des figurations confinées dans des manuscrits, les livres d'heures par exemple, accessibles seulement aux lettrés. 